A Sociological Study on University Students' Problems

$$
\text { and Their Family Context: }
$$

With Special Reference to the University of Sri

$$
\text { Jayewardenepura }
$$

\title{
By
}

Mohotti Arachchige Nayana Rasanjalee Mohottige Perera

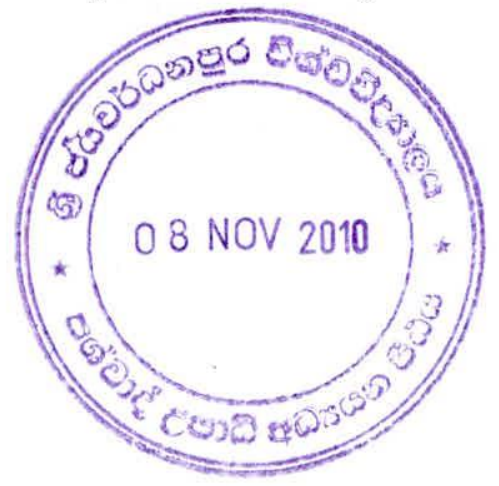

Thesis Submitted to the University of Sri Jayewardenepura for the award of the Degree of Doctor of Philosophy in Sociology on 29th December 2009 
Department of Sociology \& Anthropology

Faculty of Arts

University of Sri Jayewardenepura

04.11.2010

It is certified that Mrs. Mohotti Arachchige Nayana Rasanjalee Mohottige Perera (GS/SS/2498/2005) has carried out all amendments as suggested at the Viva Voce Examination to our entire satisfaction.

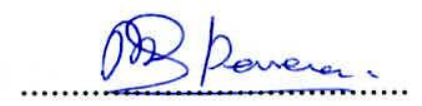

Dr. M C S Perera

Supervisor

Senior Lecturer

Department of Sociology \& Anthropology

Faculty of Arts

University of Sri Jayewardenepura

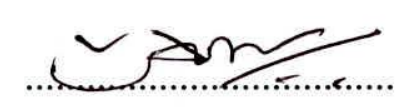

Dr. P N De S Abayasundara

Supervisor

Senior Lecturer

Department of Sociology \& Anthropology

Faculty of Arts

University of Sri Jayewardenepura 


\section{Declaration of the Candidate}

This research study for the $\mathrm{PhD}$ thesis was conducted by me under the supervision of $\mathrm{Dr}$. M C Swarnalatha Perera and Dr. P N De S Abayasundara, Senior Lecturers of the Department of Sociology and Anthropology of the University of Sri Jayewardenepura. I certify that this thesis has not been submitted in whole or in part to any university or any other institution or any other degree or diploma.

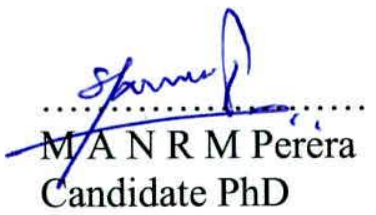

\section{Delaration of Supervisors}

We certify that the above statement made by the candidate is true and this thesis is suitable for submission to the University for the evaluation.

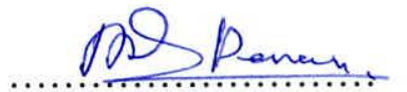

Dr. M C S Perera

Senior Lecturer

Department of Sociology \& Anthropology Faculty of Arts

University of Sri Jayewardenepura

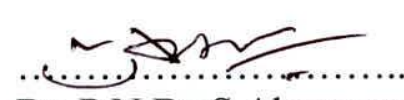

Dr. P N De S Abayasundara

Senior Lecturer

Department of Sociology \& Anthropology

Faculty of Arts

University of Sri Jayewardenepura 
This is to certify that the thesis on "A Sociological Study of University Students' Problems and Their Family Context: With Special Reference to the University of Sri Jayewardenepura" done by Mrs. Mohotti Arachchige Nayana Rasanjalee Mohottige Perera is submitted for the degree of Doctor of Philosophy in Sociology.

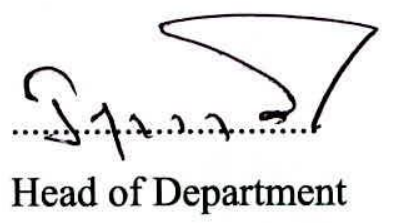

Department of Sociology and Anthropology

Faculty of Arts

University of Sri Jayewardenepura

04.11 .2010 


\section{Acknowledgements}

It is pleased of completing this doctoral thesis after heavily engaging in series of work during the last few years. For this great achievement, my personal resources could be utilized only as a result of invaluable assistance rendered by many personals. Hence, I would like to remind the names of those who were behind this successful achievement.

First of all, I am pleased to offer my sincere gratitude to my supervisors Dr. Swarnalatha Perera and Dr. Praneeth Abayasundara, Senior Lecturers of the Department of Sociology and Anthropology, Faculty of Arts of the University of Sri Jayewardenepura for their continuous endeavor instructions, encouragements specially through maintaining humanitarian relationship with me, which, as I presume, is a fundamental requirement for this type of heavy work.

I specially thank to Professor Tennison Perera, Department of Sociology and Anthropology, for his invaluable assistance rendered to me from the beginning up to the end of my research. In addition, I am thankful to Mr. Jayasundara, Head of the Department of Sociology and Anthropology for his kind assistance in facilitating all the administrative requirements.

For the primary data collection, I wanted to get official permission from each faculty of the University of Sri Jayewardenepura. Accordingly, I am thankful to Professor P Athukorala, Dean of the Faculty of Arts, Dr. S P P Amaratunge, Dean of the Faculty of Management Studies and Commerce, Professor Ajith Abeysekara, Dean of the Faculty of Applied Sciences, Professor Jayantha Jayawardene, Dean of the Faculty of Medical 
Sciences for their kind corporations in granting me the required permission to conduct the research in these faculties. I also remind the name with appreciation of former Dean of the Faculty of Management Studies and Commerce, Mr. Hilary Elmo Silva for his kind help during his tenure.

In collecting the primary data, I received tremendous help from some lecturers of four faculties. In this connection, I thankfully remind their names as Dr. Weerakoon Banda, Mr. Sharman Udayanga, Mr. Hemantha Kumara, Ms. Sumudu Perera, Mr. Dushan; lecturers of the Faculty of Management Studies and Commerce, Dr. M M Padmalal, Mr. P Dias, Dr. (Ms) Saleem, lecturers of the Faculty of Science, and Dr. Chamara, Ms. Sriyani Dharmaratne of the Faculty of Medicine, and Ms. Dr. Saman Chandra Ranasinghe, Vishaka Sooriyabandara, Ms. Manel, Dr. Shantha Wijesinghe lecturers of the Faculty of Arts for their tremendous assistance. In Addition, by sharing valuable experience, many academic and administrative personals assisted me in discussions such as Senior Student Counselor, Wardens, Sub-Wardens, Librarian, Deputy RegistrarStudents Affairs, Career Guidance Director, Welfare Director, and Medical Officer of the University of Sri Jayewardenepura. Hence, I am thankful to all of them since without their contributions, I could not have been able to do a study of this nature.

Special thank should go to Professor Z U K Ekaratne, former Director of the Staff Development Centre, University of Colombo and his staff for their invaluable assistance. My particular remembrance with thanks should go to Professor Chandra Gunawardena, former Dean of the Faculty of Education of the University of Colombo for her valuable guidance in formulating the study. Further, my sincere thanks should go to Professor A J 
Weeramunda, Department of sociology of University of Colombo for his guidance in conducting this study.

My special word of appreciation goes to Professor Sandi Oliver, former Director of Social Sciences Research Unit of the Institute of Education of the University of London for her invaluable guidance for the development of the study and for providing required literature.

Further, I am thankful to Professor Laksiri Fernando, Assistant Director of the National Centre of Advanced Studies (NCAS) for providing training opportunities for research methods and financial assistance for the successful completion of this study.

Last but not least, I am grateful for my parents and husband for their continuous assistance and their wishes to make this effort a success.

M A N Rasanjalee M Perera.

29.12.2009 


\section{TABLE OF CONTENTS}

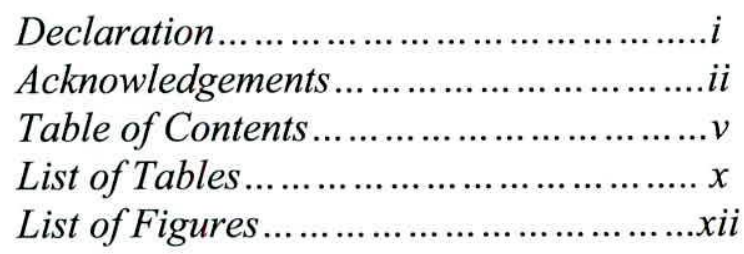

\section{Contents}

\section{CHAPTER 01-Introduction and Methodology of the Study}

1.1 Overview

1.2 Significance of the study

1.3 Main Research Problem

1.4 Objective of the Study

1.5 Conceptual Framework of the Study

1.6 Study Design

$\begin{array}{ll}1.7 \text { Field of the Study } & 17\end{array}$

$\begin{array}{ll}1.8 \text { Study Population } & 18\end{array}$

$\begin{array}{ll}1.9 \text { Selection of the Sample } & 19\end{array}$

$\begin{array}{ll}1.10 \text { Sources of Data and Information } & 19\end{array}$

1.11 Techniques of Data Collection $\quad 20$

1.12 Data Analysis 23

1.13 Limitations of the Study 23

$\begin{array}{ll}1.14 \text { Chapterization of the Thesis } & 24\end{array}$

\section{CHAPTER 02 - Background of the Field of Study:}

The University of Sri Jayewardenepura

2.1 Location of the University 28

2.2 Origin and the Evolution of the University 28

2.3 Mission of the University 35

2.4 Student Population 36

2.5 Organizational Structure of the University 36

2.6 Important Landmarks of the University 37

$\begin{array}{ll}2.7 \text { Surrounding Environment and Facilities } & 38\end{array}$ 

CHAPTER 03 - Review of Relevant Literature

3.1 Theoretical Framework $\quad 40$

3.1.1 Theory of Education $\quad 41$

3.1.2 Functional Theory $\quad 42$

3.1.3 Attachment Theory 44

3.1.4 Interaction Theory 46

3.1.5 Social Exchange Theory $\quad 47$

3.1.6 Conflict Theory 48

3.1.7 Psychoanalytic Theory 49

3.1.8 Theory of Understanding Personality 49

3.1.9 Need Theory $\quad 52$

3.2 Studies Conducted on Students Issues $\quad 54$

3.2.1 University Subculture $\quad 55$

3.2.2 Some Important Empirical Evidences of Student Issues 57

3.3 Impact of Family on Students $\quad 63$

3.3.1 Parents Styles and their Effects 65

3.3.2 Economic Status of Family $\quad 68$

$\begin{array}{ll}\text { 3.3.3 Social Status of Family } & 71\end{array}$

$\begin{array}{ll}\text { 3.3.4 Parents' Education Level } & 73\end{array}$

3.3.5 Impact of Parental Conflicts $\quad 74$

$\begin{array}{ll}\text { 3.4 Personal Problems } & 79\end{array}$

3.4.1 Social Relationships $\quad 81$

3.4.2 Violent Behaviour $\quad 83$

3.4.3 Use of Drugs and Alcohol $\quad 84$

3.4.4 Sexual Behaviour $\quad 86$

$\begin{array}{ll}\text { 3.4.5 Political Problems } & 87\end{array}$

3.4.6 Economic Problems 94

3.4.7 Psychological Problems 96

3.5 The Issues Related to Education Environment 100

3.5.1 Lack of Physical Resources 102

3.5.2 Medium of Education 103

3.5.3 Accommodation Facilities 104

3.5.4 Food and Nutrition 107

$\begin{array}{ll}\text { 3.5.5 Library Facilities } & 108\end{array}$ 
3.5.6 Recreation and Relaxation $\quad 109$

3.5.7 University Education Reforms 110

3.5.8 Teacher Student Relationship 111

3.5.9 Impact of Peer Groups 114

3.5.10 University Counseling Service 116

CHAPTER 04 - University Education in Sri Lanka

4.1 Definitions of University 122

$\begin{array}{ll}4.2 \text { University as an Organization } & 124\end{array}$

$\begin{array}{ll}4.3 \text { Objectives of University } & 124\end{array}$

4.4 Objectives of University Education in Sri Lanka 127

4.5 Origin and Expansion of Universities 128

4.6 University System in the Modern World 132

4.7 University Education in Sri Lanka 135

4.8 University Education Reforms in Sri Lanka 139

4.9 Problems Faced by the Current University System 142

4.9.1 General Views 143

4.9.2 Curriculum and Teaching Learning Process 144

4.9.3 Graduates' Unemployment Problem 145

4.9.4 Indiscipline Activities of Students 148

4.9.5 Closing Universities 152

4.10 University Students' Needs 153

4.11 University Students' Problems in World Context 155

4.11.1 Personal Problems 156

4.11.2 Academic Problems 159

4.12 University Students Problems in Sri Lanka 163

\section{CHAPTER 05 - Impact of Family on Education}

$\begin{array}{ll}5.1 \text { Overview } & 165\end{array}$

5.2 Definitions of Family 166

$\begin{array}{ll}5.3 \text { Types of Family } & 167\end{array}$

5.4 Changes in Family 168

$\begin{array}{ll}5.5 \text { Impact of Changes in Women's Role } & 170\end{array}$

5.6 Family as the Basic Social Institution 172 
5.6.1 Family as an Agent of Socialization Process

5.6.2 Family as an Introducer of Values and Norms

5.6.3 Providing Emotional Support

5.6.4 Development of Self-Esteem

5.7 Communication within the Family

5.8 Conflicts and Conflict Resolution

\section{CHAPTER 06 - Analysis and Discussion}

6.1. Personal Information

6.1.1 Engage in Occupations

6.1.2 Additional Courses Following

6.1.3 Students' Love Affairs

6.1.4 Social Relationship

6.2. Family Background

6.2.1 Size of Family

6.2.2 Parents' Education Level

6.2.3 Parents' Occupation

6.2.4 Family Income Level

6.2.5 Communication with Family

6.2.6 Emotional Bonds with Family

6.3 Influence of Education Institution

6.3.1 Accommodation Related Issues

6.3.2 Food and Nutrition Issues

6.3.3 Medium of Instruction

6.3.4 Quality and Relevancy of Degree Programmes

6.3.6 Effectiveness of Teaching Methods 267

$\begin{array}{ll}\text { 6.3.7 Teaching Equipments } & 270\end{array}$

$\begin{array}{ll}\text { 6.3.8 Evaluation Methods } & 273\end{array}$

$\begin{array}{ll}\text { 6.3.9 Library Facilities } & 276\end{array}$

$\begin{array}{ll}\text { 6.3.10 IT Skills } & 278\end{array}$

6.3.11 University Environment 280

6.3.12 Hygienic Facilities $\quad 282$ 
6.3.13 Financial Aids from the University 284

6.3.14 Opportunities to Improve Skills 286

6.3.15 Recreation and Relaxation Facilities 288

6.3.16 Teacher-Student Relationship 290

6.3.17 Counseling Service 296

6.3.18 Career Guidance Unit 301

6.4 Main Problems Faced by the Students 303

6.4.1 Family Problems 305

6.4.2 Personal Problems 307

6.4.3 Economic Problems 309

6.4.4 Political Problems $\quad 310$

6.4.5 Physical Problems $\quad 312$

6.4.6 Psychological Problems 313

6.4.7 Education Problems 315

6.4.8 Severe Problems Faced by the Students 316

6.4.9 Students' Happiness $\quad 319$

CHAPTER 07 - Conclusion and Recommendations

$\begin{array}{ll}7.1 \text { Conclusions } & 321\end{array}$

$\begin{array}{ll}\text { 7.2 Recommendations for Policy Implications } & 337\end{array}$

$\begin{array}{lr}\text { References } & \mathbf{3 4 8}\end{array}$

$\begin{array}{ll}\text { Annexure } & 368\end{array}$ 


\section{LIST OF TABLES}

Table

Page

Table 1.1 - Data and Information Needed and Questions Raised 21

Table 3.1 - Need Hierarchy

Table 3.2 - University Students' Educational Problems in Some Countries $\quad 101$

Table 3.3 - Comparisons between University Students Educational Problems in Sri Lanka and Some Developed Countries 118

Table 4.1 - University Acts and their Outcomes 139

Table 6.1 - Age of the Students 192

Table 6.2 - Age and Faculty 193

$\begin{array}{ll}\text { Table 6.3 - Age and Sex } & 194\end{array}$

Table 6.4 - Sex and Faculty 194

Table 6.5 - Students Enrollment by Nationality and Religion 196

Table 6.6 - Students Enrolments by the District and Faculty 197

Table 6.7 - Faculty and Province 198

Table 6.8 - Students' Occupations while Studying in the University 200

Table 6.9 - Additional Courses 204

Table 6.10 - Love Affaires 205

Table 6.11 - Students' Social Relations with Others 208

Table 6.12 - Number of Family Members $\quad 209$

Table 6.13 - Parents' Level of Education $\quad 211$

Table 6.14 - Parents Occupational Level 214

Table 6.15 - Income Level of Family 216

Table 6.16 - Communication with Family 224

Table 6.17 - Emotional Bonds between Students and their Family 226

Table 6.18 - Residential Place of Students $\quad 232$

Table 6.19 - Space Students Have at their Residing Places 236

Table 6.20 - Surrounding Environment of Students' Residence 237

Table 6.21 - Distance to the University from Residential Place 238

Table 6.22 - Students Satisfaction on their Food 240

Table 6.23 - Satisfaction of University Canteen 245

Table 6.24 - Faculty and Medium of Instruction 255 
Table 6.25 - Satisfaction of Medium of Instruction 262

Table 6.26 - Satisfaction of Degree Programs 264

Table 6.27 - Satisfaction of Classroom Needs 266

Table 6.28 - Satisfaction of Teaching Methods 268

Table 6.29 - Satisfaction of Teaching Equipments used by Lecturers 270

Table 6.30 - Satisfaction on Evaluation Methods 273

Table 6.31 - Library Facilities $\quad 276$

$\begin{array}{ll}\text { Table } 6.32 \text { - Satisfaction of IT Skills } & 279\end{array}$

Table 6.33 - Free Environment at the University 281

Table 6.34 - Friendly Environment at University 282

Table 6.35 - Hygienic Facilities Students Have within the University 282

Table 6.36 - Satisfaction of Financial Aids Receive from the University 284

Table 6.37 - Satisfaction of Opportunities Students Have to Develop their Talents 287

Table 6.38 - Facilities Students Have for Recreation and Relaxation 288

Table 6.39 - Teacher Student Relationship $\quad 291$

Table 6.40 - Teachers' Help to Solve Students' Problems 295

Table 6.41 - Usefulness of University Counseling Service 297

Table 6.42 - Usefulness of Career Guidance Unit 302

Table 6.43 - Main Problems Faced by the Students 304

Table 6.44 - Family Support for Personal Matters 308

Table 6.45 - Family Supports on Psychological Problems 314

Table 6.46 - Major Problems Faced by the Students 317

Table 6.47 - Self Evaluation on Their Happiness 320 


\section{LIST OF FIGURES}

Figure No

Figure 1.1 - Triangular Relationships of Students' Problem 16

Figure 1.2 - Variables that Affect on Students' Problems 17

Figure 3.1 - Variables that Affect on Students' Problems 63

Figure 3.2 - Lifespan Perspective: Bronfenbrenner's Environnemental Model 82

Figure 4.1 - Model of Higher Education System 133

Figure 4.2 - Evolution of Universities in Sri Lanka up to $1972 \quad 138$

Figure 6.1 - Triangular Relationships of Students' Problem 191

Figure 6.2 - Age Distribution of the Sample 192

Figure 6.3 - Parents' Education $\quad 212$

Figure 6.4 - Parents' Occupation 215

Figure 6.5 - Family Income $\quad 217$

Figure 6.6 - Influence of Family on Education 223

Figure 6.7 - Distance to the University vs. Performance 238

Figure 6.8 - Students' Satisfaction on Food 239

Figure 6.9 - Students' Satisfaction over the University Canteen 246

Figure 6.10 - Consequences of Going Home Frequently 250

Figure 6.11 - Wider Implications of Poor English Proficiency 261

Figure 6.12 - Satisfaction over Degree Programs 265

Figure 6.13 - Higher Performance through IT 280

Figure 6.14 - Main Reasons for Seeking Helps from Counseling Centre 301

Figure 6.15 - Major Problems 304

Figure 6.16 - Family Problems vs. Educational Problems 306

Figure 6.17 - Personal Problems vs. Educational Problems 308

Figure 6.18 - Economic Difficulties and Poor Results 310 


\title{
A Sociological Study on University Students' Problems and Their Family Context: \\ With Special Reference to the University of Sri Jayewardenepura
}

\section{A N Rasanjalee M Perera}

\begin{abstract}
Education is one of basic needs and in turns a right of all human beings. Even though, universities are considered as excellent centres for education, some students cannot gain its' full benefits due to the various reasons including students' problems. Student problems affect severely on their learning. Most of problems are multifaceted and arisen due to multiple reasons. A purposeful and conscious attempt by each stakeholder is needed to establish a proper learning atmosphere in universities. This means that for a proper learning environment, responsibility of university as well as families of students are equally important. Even though the university authority has already taken several steps in reforming university system, without having proper knowledge of students' problems it would not be easy to analyse such problems. Wrong or inadequate analysis of these problems is another problem in planning, implementing of solutions, and in turns gaining expected results successfully.
\end{abstract}

This study identified a triangular relationship regarding the university students' problems as problems arisen due to students' personal qualities, their family backgrounds and education institution. The main objective of this study is to investigate the students' problems and relationship with their family backgrounds. This objective was achieved through examining students' personal background related problems, examining students' family background related problems, identifying problems related to the university 
environment, and to disseminating the findings of the research in order to educate stakeholders of the university education for the policy decisions.

University of Sri Jayewardenepura was selected as the field of study. It was selected a sample of students including 1000 students as 400 from Faculty of Management Studies and Commerce, 300 from Faculty of Arts, 150 from Faculty of Science and 150 from Faculty of Medicine. Data collection was made by means of Questionnaire Survey, Group Discussions, In-depth Interviews, and Contacting Experts. Collected data were tabulated into tables and charts according to the necessity to trace distinguished set objectives using SPSS software. Secondly, by synthesizing and analyzing gathered data and theory, critical discussions were made to reach the objectives of the study. For this purpose, statistics such as Mode, Mean, Medium, Percentage etc were applied. Descriptive analysis technique was mainly adopted.

This study clearly found that there is a closer relationship between students' problems and socio-economic backgrounds of their families. Except some specific problems that are directly related with the education institution such as examination problems, inadequate resources, workload etc, almost all other problems are directly or indirectly related with students' family backgrounds. At the same time, students in the Arts faculty have more problems than the other students. Finally, it is proposed some new researchable problems such as "The effectiveness of institutional efforts in analysing students' problems", "The effectiveness of mechanisms that students take to solve their problems", and "How do parents keep eye on their students' education at the university?" In fact, these are possible new research on the same issue in three different angles. 